\title{
Improvement of thermal insulation of residential buildings' facades via acoustic insulation
}

\author{
J. A. E Paris-Newton ${ }^{\mathrm{a} *}$, E. Prokofieva ${ }^{\mathrm{a}}$, N. Henry ${ }^{\mathrm{a}}$ \\ ${ }^{a}$ Building Performance Centre, Edinburgh Napier University, 42 Colinton Road, Edinburgh, EH10 5BT, UK
}

\begin{abstract}
The European community has been undertaking noise mapping of major cities and transportation routes over the last decade. Implementation of the action plan to achieve reduction in people noise exposure is a key aim of the European Noise Directive (END) action planning.

The French Environment and Energy Management Agency (ADEME) and Réseau Ferré de France (RFF) combine their resources to reduce the noise exposure of noise sensitive receivers (NSRs) near railway lines. The acoustic insulation of façades near railway lines is quantified and improved if necessary. As part of these operations, a parallel improvement to the thermal performance of the façades is often possible, and may be incorporated into the acoustic mitigation designs.
\end{abstract}

This paper aims to evaluate the acoustic and thermal improvements achieved during an EU pilot project concerned with the mitigation of freight train noise in three towns in the Rhône-Alpes region of France. Calculations of both the energy consumption and sound insulation of NSR façades prior to mitigation work are compared with measurements undertaken following the façade upgrades. This study focuses on a sampling of typical buildings built prior to 1978 (over 900 properties).

(C) 2015 The Authors. Published by Elsevier Ltd. This is an open access article under the CC BY-NC-ND license

(http://creativecommons.org/licenses/by-nc-nd/4.0/).

Peer-review under responsibility of the CENTRO CONGRESSI INTERNAZIONALE SRL

Keywords: Noise Insulation, Thermal insulation, Energy feedback, Electricity and gas consumption.

\footnotetext{
* Corresponding author. Tel.: 0044131455 5115; fax: 00441314555121.

E-mail address:j.paris@napier.ac.uk
} 


\section{Introduction}

People are likely to be exposed to various noises throughout their lives for short or long periods of time. When the exposure to noise and vibration is continuous, the effect on the health and wellbeing of the person could be significant and should be avoided or reduced where possible.

Following a proposal by the Commission adopted in 2000, the European Parliament and Council adopted European Noise Directive 2002/49/EC relating to the assessment and management of environmental noise, also known as the "END". The END aims to "define a common approach intended to avoid, prevent or reduce on a prioritised basis the harmful effects, including annoyance, due to the exposure to environmental noise" [1].

The Directive is applicable to the noise emitted by road and rail vehicles and infrastructure, aircraft, outdoor and industrial equipment and mobile machinery. The main principles of the Directive are as follows:

- Monitoring the environmental problem; by requiring competent authorities in Member States to draw up "strategic noise maps" for major roads, railways, airports and agglomerations, using harmonised noise indicators $\mathrm{L}_{\text {den }}$ (day-evening-night equivalent level) and $\mathrm{L}_{\text {night }}$ (night equivalent level). These maps will be used to assess the number of people annoyed and sleep-disturbed respectively throughout Europe.

- Informing and consulting the public about noise exposure, its effects, and the measures considered to address noise, in line with the principles of the Aarhus Convention.

- Addressing local noise issues by requiring competent authorities to draw up action plans to reduce noise where necessary and maintain environmental noise quality where it is good. The directive does not set any limit value, nor does it prescribe the measures to be used in the action plans, which remain at the discretion of the competent authorities.

- Developing a long-term EU strategy, which includes objectives to reduce the number of people affected by noise in the longer term, and provides a framework for developing existing Community policy on noise reduction from source [2].

\section{Addressing noise source issues}

If the noise source is mobile (i.e. airplane, train, car) along a transportation line, it is difficult to fix the noise and vibration mitigation solutions to such sources, and the treatment has to be provided to the line rather than to the moving object. The most typical solution in these situations is a noise barrier constructed from any relevant material placed between the side of the transportation line (airfield, railway) and the nearest noise sensitive location (i.e. residential property, schools or health centres).

In some cases, however, the barrier cannot be installed between the noisy location and the receiver position, i.e. if the wall of the residential building forms the boundary of the transportation line or is located in the near vicinity to it. In this case, the façade of the Noise Sensitive Receiver may be upgraded following the CERTU guideline [3].

\section{European Noise Directive action plan implementation in Rhône-Alpes region - Protecting houses, schools and hospitals against railway noise}

The French Environment and Energy Management Agency (ADEME) and Réseau Ferré de France (RFF) joined forces to finance [4] and support the project on European Noise Directive implementation in the Rhône-Alpes region, in proximity to a busy railway. La Voulte-sur-Rhône, Bourg-Saint-Andéol and Serrières were chosen by government bodies to benefit from a pilot project, the first of its kind in Europe. It aims to provide noise mitigation measures to dwellings identified as Noise Sensitive Receivers (NSRs) that are affected by the railway noise. 
Building Performance Centre (BPC) of Edinburgh Napier University was awarded the contract to conduct the assessment of the quality of existing facades and recommend the mitigation measures to improve the day to day life of the occupants. The project started in August 2010 and was finalised in July 2014.

The objective was to improve the acoustic comfort of the residential properties, not only against the current noise environment but also the anticipated increase of railway usage as an alternative to road transport. The treatment of these NSRs consisted in upgrading the façade insulation of the buildings, including replacement of existing windows and ventilation systems. This was fully funded by ADEME (80\%) and RFF $(20 \%)$. A total fund of 6.8 million euros was available for the upgrading works. The sound insulation performance targets for the building façades are calculated based on the rules set out in the regulatory document "Circulaire of 12 June 2001" [2] as follows:

- DnT,A,tr $\geq \mathrm{I}(6 \mathrm{~h}-22 \mathrm{~h})-40 \mathrm{~dB}$, which corresponds to an internal daytime noise limit of $40 \mathrm{~dB}(\mathrm{~A})$,

- $\quad$ DnT,A,tr $\geq \mathrm{I}(22 \mathrm{~h}-6 \mathrm{~h})-35 \mathrm{~dB}$, which corresponds to an internal night-time noise limit of $35 \mathrm{~dB}(\mathrm{~A})$,

With I, Indicator of discomfort $\left(\mathrm{I}=\mathrm{L}_{\mathrm{Aeq}}-3 \mathrm{~dB}(\mathrm{~A})\right)$. [5]

BPC was provided with noise maps which included a model of the potential railway traffic in 2030, allowing prediction of the future external noise levels at the façades. In conjunction with the local authorities in France, BPC assessed the inclusion of properties in the project according to the relevant legislation. This involved extensive site surveys, measurements of the existing performance of the chosen buildings, data analysis and provision of recommendations to establish the eligibility of the buildings for the upgrade required [6].

Acoustical surveys identified sources of acoustic weakness such as windows, doors, ventilation routes, basements, ceilings and roofs. Each survey also recorded the physical dimensions of and information on the existing power consumption of the building. Thermal performance of the houses was estimated using the software BAO Promodul Pro 2R [7].

After the works on the façade improvement were conducted by third party installers, the acoustic and thermal performance of the improved facades was assessed again and compared against the initial data and the sound insulation needed in order to obtain $35 \mathrm{~dB}(\mathrm{~A})$ indoors, this being the limit required by the above standard[4].

\section{Methodology of assessments}

\subsection{Thermal performance assessments}

Thermal assessment can be separated into two parts: calculations of U-Values for individual elements of the building (using the Software BAO Promodul 2R), and via the survey of the energy consumption within each household, verified by the energy bills. To quantify the energy efficiency of the houses, a questionnaire was sent to the landlords prior the survey, which invited the landlords to prepare their energy bills, any bills from thermal upgrading work and the associated construction permit.

U-Values for individual elements of the building (i.e. wall, roof, window) correspond to the heat loss through these parts. The lower the U-Value, the less energy loss is expected through the building element.

\subsection{Acoustic assessment}

During the survey, the acoustic assessment had been based upon either the actual measurements, or upon calculation of the insulation of the existing façades elements. The measurements were in accordance with NF EN ISO Standard 10052 [8] using a speaker as a source noise positioned outside, and recorded inside the house with windows closed. Subjective listening from inside was conducted by the acoustic experts to identify the main paths of the noise through the façades into the habitable premises.

The calculations were undertaken using software created by final year engineering Masters students specialising in acoustics and vibration from Ecole Nationale d'Ingénieurs du Mans (ENSIM), France. 


\section{Assessment of the properties}

\subsection{The sample houses}

The houses chosen for the assessment dated from the early 19th century. The make-up of the external walls was traditional stone (min thickness $300 \mathrm{~mm}$ ), with terracotta tiled roof, and internal partitions made of plasterboard. Both houses faced the railway and were not guarded from railway noise by any barrier, fence or vegetation.

\section{Details of House A:}

This house was detached and was fitted with wooden single glazed windows. No ventilation was installed in dry rooms; only one extraction fan was installed on an external wall in the bathroom, but nothing in the kitchen. Ventilation was considered to be via open windows and air gaps between the frame and the window panels. House A was located within 15 meters of the railway line, and the truck line ran along the house façade at the same level as the ground floor of the house.

Gas heating was installed in this house with use of electricity for lights and appliances.

\section{Details of House B:}

This house was semi-detached and was fitted with old wooden double-glazed windows prior 1990. No ventilation was installed in dry-rooms; no extraction fan was installed in the bathroom, kitchen or toilets. The ventilation was considered to be via open windows and air gaps between the frame and the window panels. House B was located less than 5 meters from the railway line, and the truck line ran at the first floor level.

A heating oil system was installed in this house with use of electricity for lights and appliances.

\subsection{House surveys}

The survey demonstrated that the occupants of the houses were complaining about the railway noise being audible in their living rooms and bedrooms, especially during the hot periods when the windows had to be kept open. The initial assessment demonstrated low level of acoustic and thermal performances for each house façade.

\subsection{Initial assessment results}

The results of the thermal surveys are presented in Figure 1 for House A and Figure 2 for House B. Acoustical surveys conducted for both houses identified sources of acoustic weakness such as windows, doors, ventilation routes, external wall. Each survey also recorded physical dimensions and information on the existing energy consumption of the building.
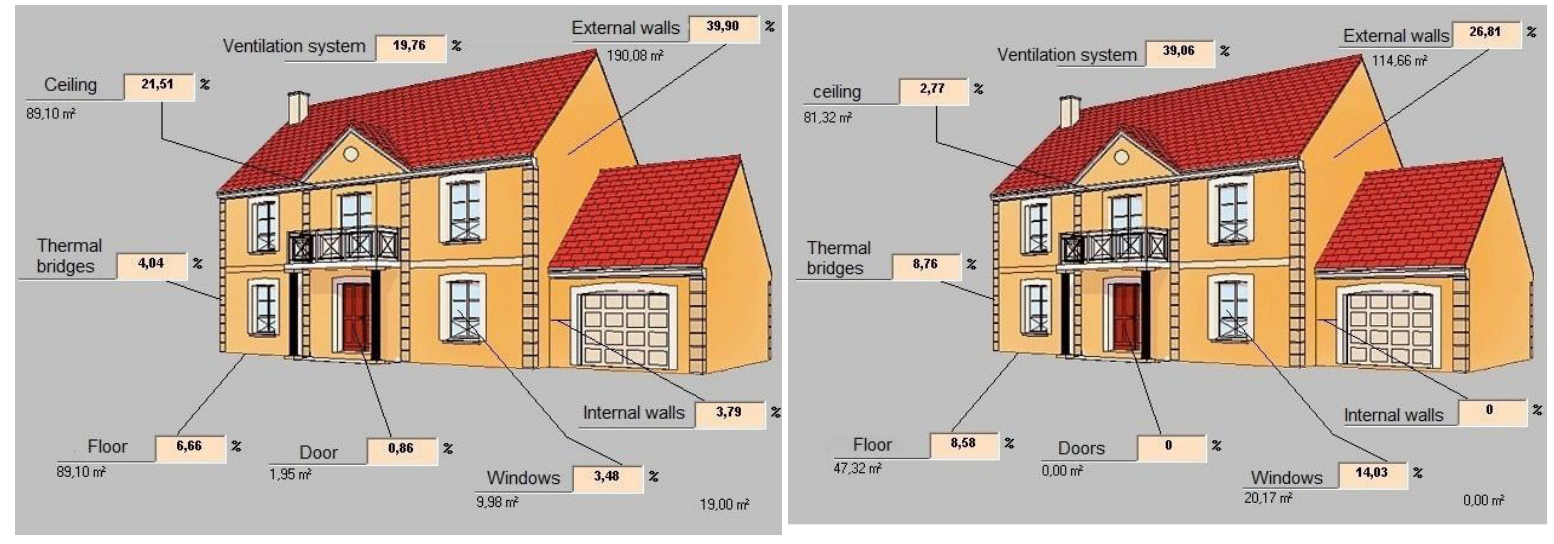

Figure 1. (a) Distribution of the heat loss - House A; (b) Distribution of the heat loss - House B 


\subsection{Materials}

The results of the acoustic assessment suggested that the following works were required for the houses (Table 1).

Table 1. Details of proposed upgrade works

\begin{tabular}{|c|c|c|c|}
\hline Type of work & House A & & House B \\
\hline Upgrading windows & $\mathrm{Rw}+\mathrm{Ctr} \quad 40 \mathrm{~dB}$ & & $\mathrm{Rw}+\mathrm{Ctr} \quad 44 \mathrm{~dB}$ \\
\hline Ventilation system & $\begin{array}{l}\text { Through wall vents }\left(D_{\text {n.e.w }}+C_{t r}\right. \\
\left.\text { with air debit of } 45 \mathrm{~m}^{3} / \mathrm{h}\right)\end{array}$ & $46 \mathrm{~dB}$ & Dual-flow ventilation \\
\hline External wall insulation & $\mathrm{N} / \mathrm{A}$ & & $\begin{array}{l}\text { Plasterboard }(16 \mathrm{~kg} / \mathrm{m} 2 \text { with } 150 \mathrm{~mm} \\
\text { insulation within a } 200 \mathrm{~mm} \text { cavity }\end{array}$ \\
\hline
\end{tabular}

A ventilation system was added to each house, to allow the occupants to maintain air circulation and quality within the premises without opening the windows on the noise-exposed façade. The installation of properly sealed windows dramatically improved the air tightness of the property. Without an appropriate ventilation system, health issues for the occupants can be linked to air quality and humidity issues within the building.

The quotes prepared by a third party installer were checked and approved by engineers from BPC. For House A 44.2/8Argon/10 was validated, and 44.2/18/10 was validated for House B. The upgrade works were then completed under the supervision of BPC. As these upgrades were financed by government bodies, all the installed windows were tested in accordance with NF EN ISO 10052[8].

\subsection{Post-completion acoustic assessment results}

The measurements of the facades of both houses were conducted using the same methodology in accordance with NF EN ISO 10052. The results of upgraded façade performances are shown in Table 2.

Table 2. Acoustic performance of upgraded houses compared to initial measurements

\begin{tabular}{llll}
\hline Type of work & Initial acoustic performance & Upgraded acoustic performance & Improvement \\
& $\mathrm{D}_{\mathrm{nT}, \mathrm{w}}\left(\mathrm{C}_{1} ; \mathrm{C}_{\mathrm{tr}}\right) \mathrm{dB}$ & $\mathrm{D}_{\mathrm{nT}, \mathrm{w}}\left(\mathrm{C}_{1} ; \mathrm{C}_{\mathrm{tr}}\right) \mathrm{dB}$ & $\mathrm{D}_{\mathrm{nT}, \mathrm{w}}\left(\mathrm{C}_{1} ; \mathrm{C}_{\mathrm{tr}}\right) \mathrm{dB}$ \\
\hline House A & $30(-1 ;-3)$ & $41(-1 ;-3)$ & 11 \\
House B & $32(-1 ;-3)$ & $47(-1 ;-4)$ & 14 \\
\hline
\end{tabular}

The results show that improvement across entire range of frequencies was achieved once the window/ventilation upgrades were provided. It was also demonstrated that houses which received the additional façade upgrade got additional insulation improvement for mid frequency ranges.

\subsection{Post-completion thermal results}

Additionally an assessment was conducted on the improvement to thermal performance of the houses. Prediction of the heat loss was performed using software simulation. Some sample prediction results are shown in Table 3 .

Table 3. Thermal performance of upgraded houses compare to initial ones

\begin{tabular}{|c|c|c|c|c|c|}
\hline \multirow[t]{2}{*}{ House } & \multicolumn{2}{|c|}{$\begin{array}{c}\text { U-Value of windows, } \\
\text { W/(m2.K) }\end{array}$} & \multicolumn{2}{|c|}{$\begin{array}{l}\text { Percentage of heat loss due } \\
\text { to the ventilation system }\end{array}$} & \multirow{2}{*}{$\begin{array}{c}\text { Consequences on energy } \\
\text { bills } \\
\text { (percentage) }\end{array}$} \\
\hline & Before & After & Before & After & \\
\hline House A & 4.2 & 2.3 & $20 \%$ & $6 \%$ & Decrease of $9 \%$ \\
\hline House B & 2.8 & 1.4 & $39 \%$ & $12 \%$ & Decrease of $18 \%$ \\
\hline
\end{tabular}




\section{Conclusions and Future work}

Upgrading windows has more consequences for the sound insulation than for energy savings in the case of old properties, as the windows at one of the facades of the building represent a reasonably low percentage of the heat loss. However the change the windows and, as the result of this, the upgrade of the ventilation system has had significant consequences on energy use within the households. These changes had a direct effect on the energy bills paid by the occupants of both households, with clearly demonstrated decrease of the costs of heating the properties.

From acoustic point of view the health and well-being of the occupants of the house also changed significantly and confirmed via measurements and then the post-completion survey. In both cases the occupants became less exposed to the noise during the day and night, with windows closed and without compromise on ventilation conditions.

For future research within the scope of the project it would be interesting to compare the improvement between the different types of properties, such as flats (with larger percentage of façades covered with windows), properties built in the 1970s, and modern houses with embedded acoustic and thermal improvement measures.

\section{Acknowledgment}

The authors wish to thank the co-founders of this project ADEME and RFF, to Edinburgh Napier University including Sottish Energy Centre (SEC), Pr. R.S Smith and R.G. Mackenzie, for their help with the project.

\section{References}

[1] Circulaire of 25 May 2004 on land transport infrastructure noise, Legifrance (2004)

[2] Circulaire of 12 June 2001 on the observatory land transport noise - acoustic treatment of Noise Sensitive Receivers, Legifrance (2001)

[3] CERTU "Sound insulation of facades - technical and administrative guide for the treatment of Noise Sensitive Receivers" (2003)

[4] French Ordinance of 3 May 2002 taken for the application of French Decree ${ }^{\circ}$ 2002-867 dated of 3 mai 2002 on subsidies granted by the Government for Sound insulation of façades treatment of Nosie Sensitive Receivers due to national road and rail networks (May 2002)

[5] French Ordinance of 08 November 1999.

[6] Improving existing façade insulation against railway noise, J.A.E. Paris-Newton, D. Chapman, C. Luciani and R. G. Mackenzie, Acoustics 2012, Nantes, France

[7] http://www.logiciels-bao.fr/26/bao-pro-2r

[8] NF EN ISO 10052 - Acoustics -- Field measurements of airborne and impact sound insulation and of service equipment sound -- Survey method, AFNOR (2005) 